\title{
Rare mimic of recurrent anaphylaxis
}

\author{
Carlo Yuson, Frank Kette, Pravin Hissaria, William Smith
}

Department of Clinical Immunology and Allergy, Royal Adelaide Hospital, Adelaide, South Australia, Australia

\section{Correspondence to Dr Carlo Yuson, \\ chinoyuson@gmail.com}

Accepted 19 January 2019

\section{SUMMARY}

The distinction between true anaphylaxis and conditions that mimic it can be challenging. We present the unique case of a 23-year-old woman treated for recurrent episodes of anaphylaxis over the course of 11 years and the subsequent discovery of an unlikely condition. We also discuss our approach in managing cases where an anaphylactic mimic is suspected.

\section{BACKGROUND}

Hospital admissions due to anaphylaxis in Australia have increased in recent decades. ${ }^{1}$ While most inciting agents will be identified through history and investigation, a proportion will also remain unknown. Present within this cohort are a handful of conditions that may present as anaphylaxis but are unrelated to allergy. We present the unique case of a young woman who carried the label of recurrent anaphylaxis over the course of many years, which then led to the discovery of an unlikely condition.

\section{CASE PRESENTATION}

A 23-year-old woman was referred to the Royal Adelaide Hospital (RAH) from a regional hospital in South Australia after 40 anaphylactic episodes in the span of 4 weeks. She had 10 presentations to the emergency department (ED), with reported symptoms of unilateral facial swelling, dyspnoea and chest tightness, as well as labile blood pressure on one occasion. As she met criteria for anaphylaxis, ${ }^{2}$ epinephrine was given on each presentation, including an epinephrine infusion in one instance.

She had a history of asthma, seasonal rhinoconjunctivitis and gluten intolerance, and was reported to be allergic to peanuts, tree nuts, eggs, coconut, radiocontrast media and local anaesthetics among other things. Her medications on presentation included loratadine $20 \mathrm{mg}$ three times a day, cyproheptadine $8 \mathrm{mg}$ three times a day, montelukast $10 \mathrm{mg}$ twice a day, budesonide/eformoterol $200 / 6 \mu \mathrm{g}$ twice a day and prednisolone $25 \mathrm{mg}$ daily.

The first episode occurred 11 years previously in her home country of New Zealand. She experienced facial swelling and dyspnoea after a dental procedure using local anaesthetic at age 12. Similar symptoms recurred every few months, attributed to a variety of triggers, with no consistent pattern. This resulted in a significantly restrictive lifestyle as she avoided an increasing list of foods she considered potential allergens.

She moved to Melbourne, Australia in her early twenties and became pregnant. During this time, she had an increase in frequency of symptoms, which had evolved to include chest tightness with wheezing and occasional dysphonia. Unilateral facial swelling was still reportedly prominent though it was accompanied with mild tongue swelling. She was reviewed by an immunologist; investigations, including skin prick testing to multiple foods and aeroallergens, were negative. She was given the diagnosis of recurrent idiopathic anaphylaxis, provided an epinephrine auto-injector (Epipen) and was started on regular antihistamines. She went into premature labour and delivered at 35 weeks.

A year later, shortly before we saw her, she moved to regional South Australia where her reactions increased in frequency and severity, prompting multiple ED presentations. During these events, epinephrine did not significantly improve her symptoms. An event tryptase level remained within normal limits at $5.4 \mu \mathrm{g} / \mathrm{L}$ which was not significantly elevated from a subsequent baseline tryptase of $4.1 \mu \mathrm{g} / \mathrm{L}$. Initiation of montelukast and regular high-dose prednisolone did not decrease episode frequency.

On examination at presentation to the RAH, she was normotensive and tachycardic. She also had a scattered wheeze on auscultation. While she reported right-sided facial swelling, this was not an objective observation.

\section{INVESTIGATIONS}

We considered alternative diagnoses including bradykinin-mediated angioedema, vocal cord dysfunction or a psychosomatic reaction. While under close ward supervision, epinephrine was withheld. She subsequently had two episodes which had normal in-event tryptase and complement levels. Face and tongue swelling was reported by the patient but was not observed. Indirect laryngoscopy did not demonstrate laryngeal swelling or vocal cord dysfunction in either episode.

A head and neck CT scan was ordered to rule out anatomical causes for her symptoms. This revealed a lipoma protruding into her right pharyngeal wall, occupying the posterior cervical space and displacing neck vessels (figure 1). Interestingly, an abdominal lipoma had also been found on a recent CT scan investigating abdominal pain.

Additional history revealed that a rare autosomal dominant condition called Bannayan-Riley-Ruvalcaba syndrome (BRRS) had been diagnosed in several of our patient's close relatives. BRRS is characterised by macrocephaly, haemangiomas and lipomas. A mutation in the tumour suppressor PTEN gene, or phosphatase and tensin homologue gene, is found in $60 \%$ of the cases. ${ }^{3}$ Subsequently, 


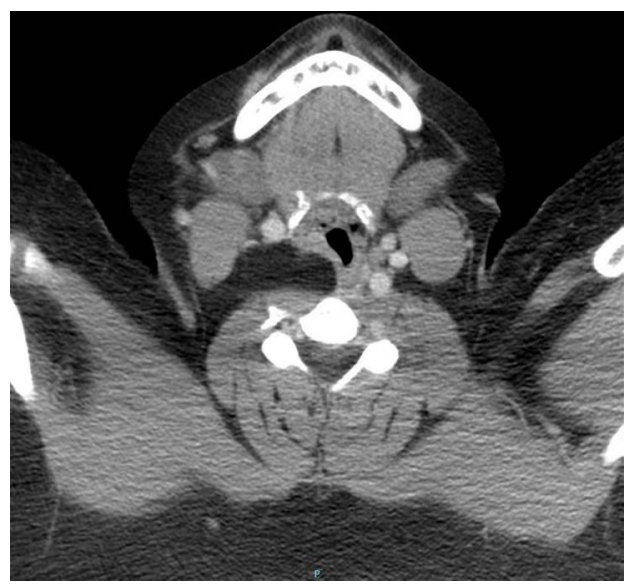

Figure 1 Cervical CT scan demonstrating a lipoma in the posterior cervical region.

next-generation sequencing and Sanger sequencing revealed a frameshift mutation of PTEN consistent with BRRS in our patient.

\section{TREATMENT}

We explained to the patient that her symptoms were likely due to pressure discomfort from the lipoma in her neck. She was reviewed by a multidisciplinary head-and-neck team consisting of respiratory physicians, ENT specialists and anaesthetists. Surgical intervention was deemed unnecessary for her neck mass and she remains under active surveillance.

We de-escalated her allergy therapy, ceasing antihistamines, montelukast and corticosteroids. We revisited the history of each of her listed allergens and challenged several putative food allergens in hospital with negative results. Having inspired the patient with confidence, we provided instruction for home challenges to other items formerly considered to be allergic triggers.

\section{OUTCOME AND FOLLOW-UP}

A year later, our patient has not used her Epipen and now enjoys foods she has avoided for many years. She has also been able to complete dental procedures previously deferred because of her local anaesthetic allergy label.

As developmental delays have been described in those with BRRS, her daughter is also undergoing close monitoring. In 4 years, our patient will begin cancer screening, as the mutation is also associated with increased predisposition to certain malignancies.

\section{DISCUSSION}

Acute presentation with dyspnoea and swelling suggests a diagnosis of angioedema or anaphylaxis. The diagnosis is often influenced by prior diagnostic labels. Our patient acquired a label of recurrent anaphylaxis, which persisted despite the lack of objectively observed signs or consistent physiological disturbances and despite normal event tryptase and normal complement levels. In a patient who presents to the ED acutely distressed and dyspnoeic, perhaps already having used his or her Epipen, the diagnosis tends not to be questioned.

When a consistent trigger for anaphylaxis cannot be identified, the term idiopathic anaphylaxis is applied. However, it is first necessary to determine that the clinical presentation is actually anaphylaxis. While our patient theoretically fulfils anaphylaxis criteria with her acute symptom onset, reported involvement of mucosal tissue and episodic dyspnoea, ${ }^{2}$ we believe that there may have been some confusion between subjective complaints (a feeling of swelling) and objective signs, for example we did not observe facial swelling during the two episodes that arose in hospital. This highlights the potential for ambiguity in the application of diagnostic criteria that might lead to overdiagnosis in the acute situation. Where there is no visible swelling of the face, tongue or oropharynx, examination of the larynx by direct or indirect laryngoscopy may confirm or rule out laryngeal oedema; this was negative in our case. Where clinical features are not obvious, a raised event serum tryptase level (compared with patient baseline) provides confirmation, although lack of tryptase elevation does not exclude anaphylaxis. Another relevant diagnostic factor is the response to acute or prophylactic antiallergic treatments, or lack thereof.

BRRS falls under the umbrella of the PTEN hamartoma syndromes that are associated with unregulated cellular proliferation leading to tumour formation. Those with the condition are at increased risk of breast, thyroid and endometrial cancer, making malignancy surveillance central to its management. ${ }^{4}$ While aggressive growth of benign tumours has been described in BRRS, ${ }^{5}$ the chronicity of symptoms and the lack of progression over the succeeding year of monitoring would suggest that this was not the case in our patient.

In the case of our patient, we speculated that the cervical lipoma might have compressed neck vessels leading to venous engorgement, or impinged on the vagus nerve causing autonomic dysregulation, and that these events mimicked anaphylaxis. However, cessation of episodes following a lengthy discussion of how the mass may affect her would imply that local neck discomfort was misinterpreted as swelling and anaphylaxis by both the patient and doctors. Reassurance has been reported as an effective treatment in some somatoform reactions mimicking idiopathic anaphylaxis. ${ }^{6}$ That she has since been able to tolerate all of her allergen challenges confirms the lack of any significant allergic process in her symptoms. Furthermore, that her anaphylaxis diagnosis continued to travel with her over many years and through different locations despite the lack of evidence supporting this highlights the tenacity of an allergic label.

\section{Learning points}

- A tryptase level should be ordered when suspecting anaphylaxis, followed by a repeat level at least $24-48$ hours after the event.

- Direct or indirect laryngoscopy should be considered when there is suspicion of laryngeal oedema.

- Anaphylactic mimics should remain a differential diagnosis in recurrent episodes of idiopathic anaphylaxis.

Contributors All authors have significantly contributed to this manuscript. CY, FK, $\mathrm{PH}$ and WS were involved in the planning of the manuscript, as all were involved in managing the case. FK, PH and WS identified the salient points that should be featured in the manuscript. CY wrote the initial draft of the manuscript with revisions done by WS. CY and WS formulated the Discussion section of the manuscript. FK and $\mathrm{PH}$ were involved in minor manuscript revisions and contributed to the Discussion section as well.

Funding The authors have not declared a specific grant for this research from any funding agency in the public, commercial or not-for-profit sectors.

Competing interests None declared.

Patient consent for publication Not required.

Provenance and peer review Not commissioned; externally peer reviewed. 


\section{REFERENCES}

1 Mullins RJ, Wainstein BK, Barnes EH, et al. Increases in anaphylaxis fatalities in Australia from 1997 to 2013. Clin Exp Allergy 2016;46:1099-110.

2 Sampson HA, Muñoz-Furlong A, Campbell RL, et al. Second symposium on the definition and management of anaphylaxis: summary report-Second National Institute of Allergy and Infectious Disease/Food Allergy and Anaphylaxis Network symposium. J Allergy Clin Immunol 2006;117:391-7.

3 Lachlan KL, Lucassen AM, Bunyan D, et al. Cowden syndrome and Bannayan Riley Ruvalcaba syndrome represent one condition with variable expression and age- related penetrance: results of a clinical study of PTEN mutation carriers. J Med Genet 2007:44:579-85.

4 Hobert JA, Eng C. PTEN hamartoma tumor syndrome: an overview. Genet Med 2009:11:687-94.

5 Hendriks YM, Verhallen JT, van der Smagt JJ, et al. Bannayan-Riley-Ruvalcaba syndrome: further delineation of the phenotype and management of PTEN mutation-positive cases. Fam Cancer 2003;2:79-85.

6 Choy AC, Patterson R, Patterson DR, et al. Undifferentiated somatoform idiopathic anaphylaxis: nonorganic symptoms mimicking idiopathic anaphylaxis. J Allergy Clin Immunol 1995;96:893-900.

Copyright 2019 BMJ Publishing Group. All rights reserved. For permission to reuse any of this content visit https://www.bmj.com/company/products-services/rights-and-licensing/permissions/

BMJ Case Report Fellows may re-use this article for personal use and teaching without any further permission.

Become a Fellow of BMJ Case Reports today and you can:

- Submit as many cases as you like

- Enjoy fast sympathetic peer review and rapid publication of accepted articles

- Access all the published articles

- Re-use any of the published material for personal use and teaching without further permission

For information on Institutional Fellowships contact consortiasales@bmjgroup.com

Visit casereports.bmj.com for more articles like this and to become a Fellow 